\title{
Assessment of Building Damage in Raqqa during the Syrian Civil War Using Time-Series of Radar Satellite Imagery
}

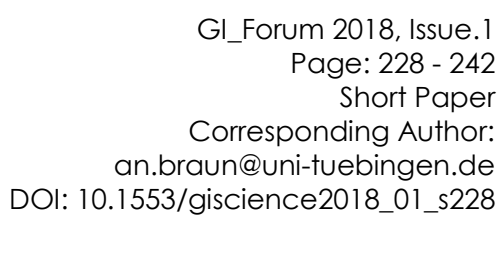

Andreas Braun

University of Tübingen, Germany

\begin{abstract}
Change detection is one of the key tasks of earth observation. In the humanitarian domain, information about the impacts of natural disasters or military conflicts are of particular interest. This study uses time-series of Sentinel-1 radar imagery to identify changes resulting from armed combats in the city of Raqqa, Syria. The concept of permanent scatterers (PS) was applied to the data for the identification of stable information, which is then used for temporal analysis of pixel amplitudes. In an urban context, this gives insights into both the locations of damage and the exact date of the destruction. Instances of damage manually identified by UNOSAT are used for validation. The study shows that Sentinel-1 data can be a suitable indicator for heavy damage, but limitations arise from the comparably low spatial resolution and in cases of moderate changes which do not affect the structure of buildings. The study demonstrates the potential of radar imagery regarding its spatial and temporal resolution and gives examples of detailed analyses at selected areas of special interest.
\end{abstract}

\section{Keywords:}

damage assessment, Synthetic Aperture Radar (SAR), change detection, civil war, timeseries analysis

\section{Introduction}

Remote sensing has proven to be a valuable source of information for the mapping of natural hazards and disasters (Joyce et al., 2009). Applications include the aftermath of single events, such as floods (Klemas, 2015), landslides (Scaioni et al., 2014) or earthquakes (Tronin, 2006), and the long-term monitoring of continuous phenomena, such as tectonic or geomorphologic movement (Alvan \& Azad, 2011), air pollution (Martin, 2008) or ecosystem degradation (Xie et al., 2008)

The possibility of accessing large image archives is especially helpful for the assessment of changes over long time periods. In this context, the temporal resolution of a sensor can become more important than its spatial resolution, because it allows both the clear 
identification of the date of occurrence of an event and the detailed monitoring of subtle changes (Lazecky et al., 2017; Gernhardt \& Bamler, 2012)

Earth observation (EO) using multi-spectral imagery is often constrained by cloud cover and shadows (Wulder et al., 2008; Giles, 2001; Pearce, 1985). This becomes a problem for timecritical applications which rely on immediate access to images, as during emergency responses (Boccardo \& Giulio Tonolo, 2015; Joyce et al., 2010). Furthermore, operational services strongly rely on data that do not risk being affected by cloud cover (Moser et al., 2017).

As a part of earth observation which is more independent of cloud cover, data from spaceborne synthetic aperture radar (SAR) have been established in the field of remote sensing applications since the 1990s. Because of the long wavelengths of the signals, they are highly capable of penetrating clouds and can also operate at night (Ulaby et al., 1982). In addition, active microwaves image different characteristics of the earth's surface, such as texture, shape, orientation, material or roughness of surfaces, from optical sensors. For these reasons, SAR remote sensing is highly suitable for applications in disaster mapping, emergency response or, more generally, in the humanitarian domain, as demonstrated in numerous studies (Braun \& Hochschild, 2017; Braun et al., 2016; Plank et al., 2016; Amitrano et al., 2013; Sato et al., 2008; Boni et al., 2007; Brekke \& Solberg, 2005; Wiesmann et al., 2004; Brakenridge et al., 2003; Wegmuller et al., 2002; Yonezawa \& Takeuchi, 2001; Lu et al., 1997).

Thanks to the availability of archived data, change detection based on multiple images taken at short intervals can be performed. While for a long time this was restricted to highresolution optical imagery, the permanent scatterer (PS) technique allows the investigation of targets over a given period using high-resolution SAR data based on the analysis of the amplitude and phase of the signal (Prati et al., 2010; Perissin \& Ferretti, 2007; Ferretti et al., 2001). This study demonstrates whether and how Sentinel-1 data can be used for damage assessment in urban areas affected by civil war.

\section{Study area and data}

\section{Raqqa}

Raqqa (or Ar-Raqqa) is a city in northern Syria with a population of around 220,000 (2004 census). It is located on the northeastern bank of the Euphrates and has a spatial extent of around $10 \mathrm{~km}$ in the east-west direction by $4 \mathrm{~km}$ in the north-south direction (Figure 1). Its surroundings are dominated by wheat and cotton cultivation; the climate is semi-arid.

Due to its strategic location in the north of the country, it was the first Syrian provincial capital to fall out of government control, starting with an occupation by rebels in March 2013 (Aljazeera, 2013). Since that time, the city and its population have been subject to various occupations and heavy battles, leading to the death of numerous civilians, and enormous damage to buildings and infrastructure. It was finally declared liberated in October 
2017 , but by that date, nearly $90 \%$ of the city had been levelled due to heavy bombardments (Malsin, 2017).

As seen in Figure 1, the city is bound by two main roads in the north and west and the Euphrates in the south. Urban roads and blocks, which are influenced by Iranian architecture, are arranged in a grid-like pattern whose centre is the former Great Mosque (Hillenbrand, 1985)

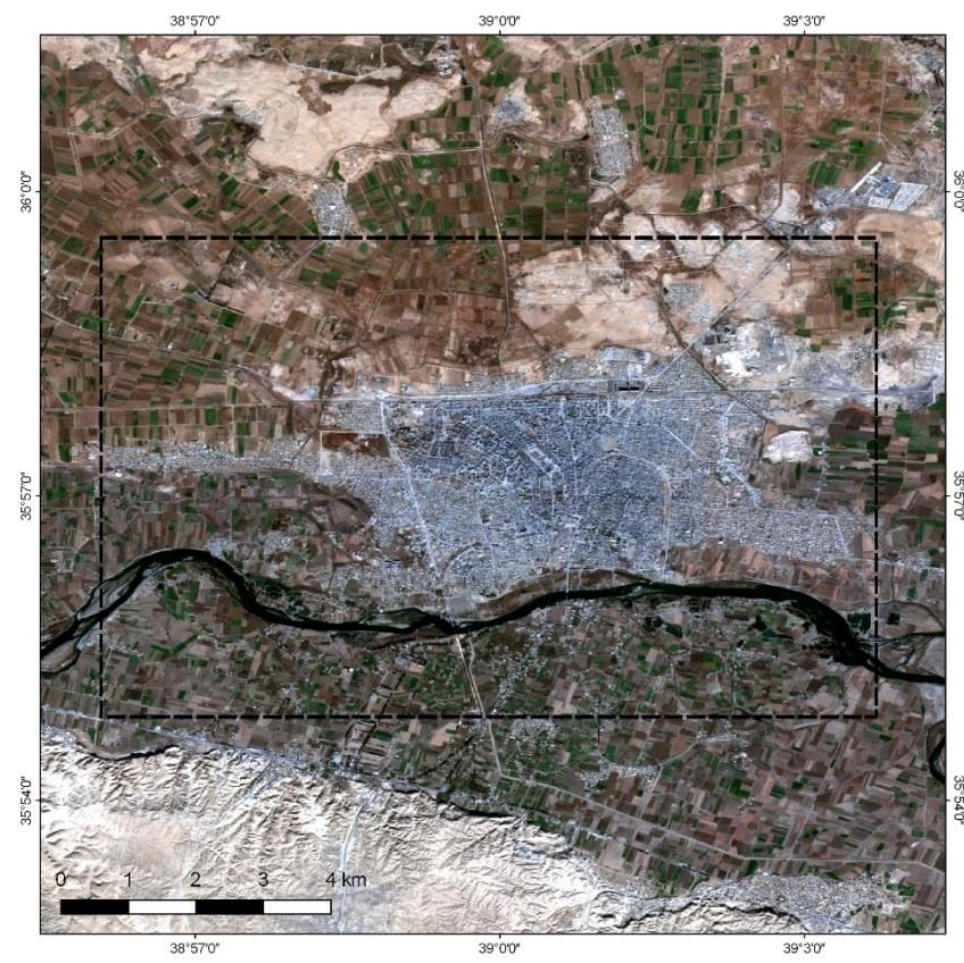

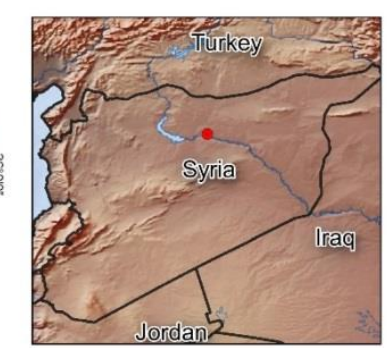

Legend

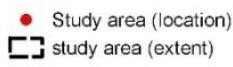

Main map: Sentinel-2 image 04.12.2017 provided by ESA

Top: Geographic map

C) Natural Earth Data

Bottom: Infrastructure of ar-Raqqa with locations for detailed analysis (c) OpenTopoMap

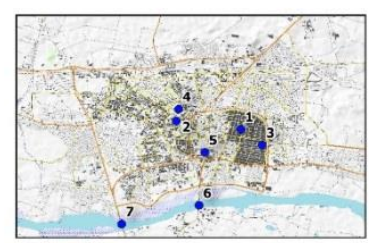

Figure 1: Location and structure of the study area. The numbers on the smaller map (bottom right) indicate the locations for the detailed analysis in section 4.3.

\section{Sentinel-1}

Thanks to the continuous acquisition of C-band radar imagery and its provision via the Copernicus programme (Panetti et al., 2014), a total of 55 Sentinel-1 images taken between $10 / 2014$ and 12/2017 were available for this study. Different intervals between the images were chosen in order to cover the largest time span possible while simultaneously keeping processing efforts low. As Figure 2 shows, intervals of 12 days were chosen for the first five months (December 2014 to April 2015) and for the whole of 2017; for the period in between, intervals of 48 days were used. This ensures that changes with high significance can be identified. Important dates, such as changes in occupation and those of military offensives, are also marked on the graph. Unfortunately, the Sentinel-1 mission only started in October 2014, so the time before the Syrian civil war and Raqqa's occupation by IS in 
March 2013 could not be analysed. But it is estimated that most of the heavy damage has been caused since 2014 (Hassan, 2017).

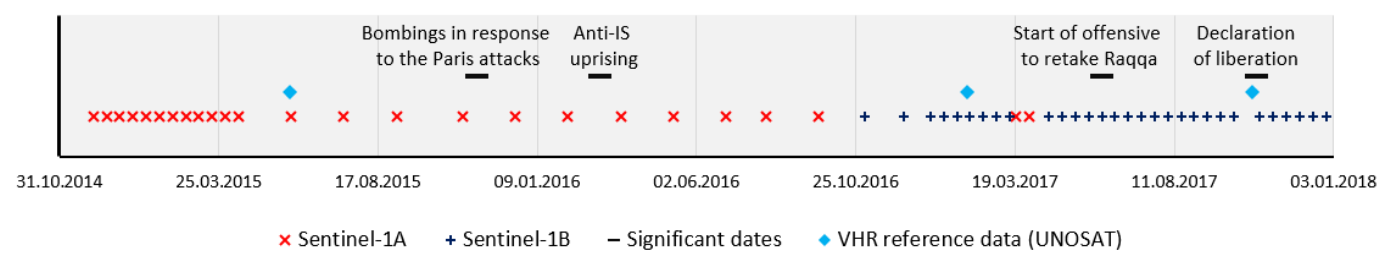

Figure 2: Temporal distribution of Sentinel-1 data used in this study

\section{Reference data}

For validation, a dataset available publicly from the UNOSAT programme of the United Nations Institute for Training and Research (UNITAR, 2017) was used. It consists of a total of 13,160 points of manually digitized damaged structures. These are based on the visual interpretation of five very high resolution (VHR) satellite images, of which three date from the period analysed. As Table 1 shows, most of the damage was detected between 03.02.2017 and 21.10.2017. This results both from the slightly higher resolution of $30 \mathrm{~cm}$ and from the fact that most of the damage was caused by the intensified battles for Raqqa after May 2017 (Hassan, 2017).

Table 1: Optical imagery of UNOSAT

\begin{tabular}{|l|l|l|}
\hline $\begin{array}{l}\text { Sensor } \\
\text { (spatial resolution) }\end{array}$ & $\begin{array}{l}\text { date of image } \\
\text { acquisition }\end{array}$ & $\begin{array}{l}\text { number of newly } \\
\text { identified points }\end{array}$ \\
\hline WorldView-1 $(50 \mathrm{~cm})$ & 22.10 .2013 & 340 \\
\hline WorldView-2 $(50 \mathrm{~cm})$ & 12.02 .2014 & 124 \\
\hline Pléiades $(50 \mathrm{~cm})$ & $29.05 .2015^{*}$ & 1,104 \\
\hline WorldView-2 $(50 \mathrm{~cm})$ & $03.02 .2017^{*}$ & 250 \\
\hline WorldView-3 $(30 \mathrm{~cm})$ & $21.10 .2017^{*}$ & 11,342 \\
\hline & ${ }^{*}=$ used for this study \\
\end{tabular}

Table 2 shows the UNOSAT damage assessment for the last period in greater detail. It breaks all changes down into their degree of confidence. This helps to ascertain the suitability of these data as a reference in this study, in particular because they were all digitized manually and never validated in the field. Around 50\% of the damage was identified with a 'very high' level of confidence. A total of 2,576 structures were labelled as 'destroyed'; these account for $20 \%$ of all identified damage. Most uncertainties occur for structures that have suffered moderate damage, because the buildings are still present, but shadows or other patterns indicate that something has changed. Impact craters in roads or open fields are also 
identified in the dataset, but they are not considered in this study. 'No change' in this context means that the structure was already identified as damaged in an earlier image, but no further change has occurred since. The table shows that only a small fraction of the data was labelled as 'uncertain'. Yet, the severity of the damage and the total number of destroyed structures should not be taken as the ultimate truth but rather help to validate the results of this study in terms of plausibility and matching spatial patterns.

Table 2: Damage identified by UNOSAT between 03.02.2017 and 21.10.2017, modified from UNITAR (2017)

\begin{tabular}{|c|c|c|c|c|c|}
\hline & & \multicolumn{3}{|c|}{ Damage confidence } & \multirow[b]{2}{*}{ sum } \\
\hline & & uncertain & medium & very high & \\
\hline \multirow{6}{*}{ 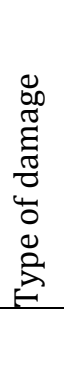 } & no change & 14 & 102 & 1 & 117 \\
\hline & impact crater & 0 & 27 & 235 & 262 \\
\hline & moderate damage & 353 & 5,117 & 23 & 5,493 \\
\hline & severe damage & 0 & 293 & 3,669 & 3,962 \\
\hline & destroyed & 0 & 750 & 2,576 & 3,326 \\
\hline & sum & 367 & 6,289 & 6,504 & 13,160 \\
\hline
\end{tabular}

\section{Methods}

\section{Pre-processing}

Sentinel-1 data were acquired in Interferometric Wide Swath (IW) mode and provided as SLC products, which include complex pixel information as well as rasters in slant geometry. Subsets of the study area (see Figure 1) were extracted and all images were co-registered to a single stack (mean RMSE for all pairs: 0.1320 mean; standard deviation: 0.0784). All data was processed in the Sarproz software (Perissin, 2018).

\section{Analysis}

The main advantage of a stack consisting of multiple SAR images is that it allows the identification of pixels which show a stable sequence of amplitude values (the measured backscatter) throughout the whole period investigated. The position of these stable targets, also called permanent or persistent scatterers (PS), can be determined with sub-pixel accuracy; their elevation can also be determined (Ferretti et al., 2001). The scattering mechanisms, identified as a function of normal baseline and Doppler centroid, can then be used to investigate changes in the targets along a timeline (Ferretti et al., 2005). In an urban context, radar amplitudes of built-up structures are enhanced due to corner reflection (Lee, 2001), and by building materials (Henderson \& Xia, 1997) and orientation towards the sensor (Ferro et al., 2011). These factors help to determine the presence or absence of buildings. 
Employing Gaussian algorithms to the temporal profile of an amplitude time-series allows the identification of the 'life time' of pixels and their underlying objects, especially their changepoints (Chambers et al., 1996). We use this to identify changes in built-up structures, most probably caused by armed conflicts.

In order to reduce the number of pixels of interest, a polygon covering the city's extent was used as a mask, leaving the permanent scatterers over the built-up area $(\mathrm{n}=46,472)$. Figure 3 shows the mean image of all S1 images (left) and the identified permanent scatterers (right). The colours indicate the stability of each PS, which was calculated based on the mean and standard deviation of all amplitude values of a pixel (Lei et al., 2013). As expected, most of them are stable during the whole period (values $>0.5$ ), which means that no distinctive change is expected at this location. However, there are also many points which are not stable during this period, as indicated by the yellow and blue colours. These will be investigated below.
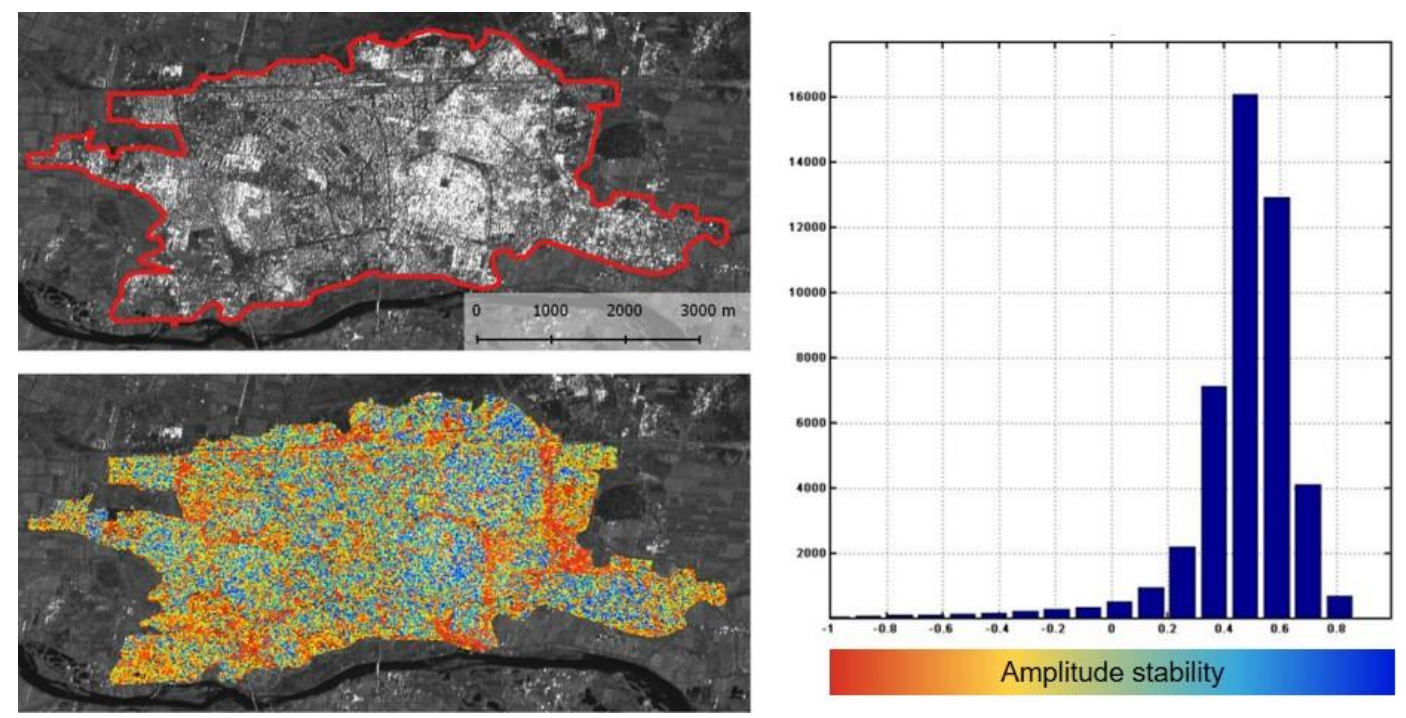

Amplitude stability

Figure 3: Mean amplitude image (top left), selected permanent scatterers (bottom left) and histogram of amplitude stability (right).

\section{Results}

\section{Temporal changes}

In the first step, PSs with a limited life-time were identified - that is, those which show a significant decrease of backscatter between two observations, which persists until the end of the period investigated (Perissin et al., 2006). A total of 3,334 PSs with a limited life-time were identified. They were plotted against the number of instances of damage derived by UNOSAT, as demonstrated in Figure 4. While there is a strong underestimation of changes of uncertain, middle and high confidence and of moderate and severe damage (see Table 2), 
the number of instances of severe damage (dark blue) strongly correlates with the number of PSs identified, which show a significant decrease over the period investigated. Later analyses show that not all of them are necessarily at the same location, but these findings indicate that Sentinel-1 data constitute a highly suitable temporal indicator for severe damage in urban areas. However, the discrepancy between roughly 2,900 destructions detected by Sentinel-1 and the total estimates of 11,300 made by UNOSAT shows the limits of radar data at this resolution: more subtle damage to buildings, such as cracked walls or partly collapsed roofs, are hardly detectable by PS techniques because their overall amplitude doesn't change significantly. Additionally, changes in colour, for example caused by fire or dust, are not detected by microwaves of this wavelength. A detailed discussion on the difficulties is given in section 5 .

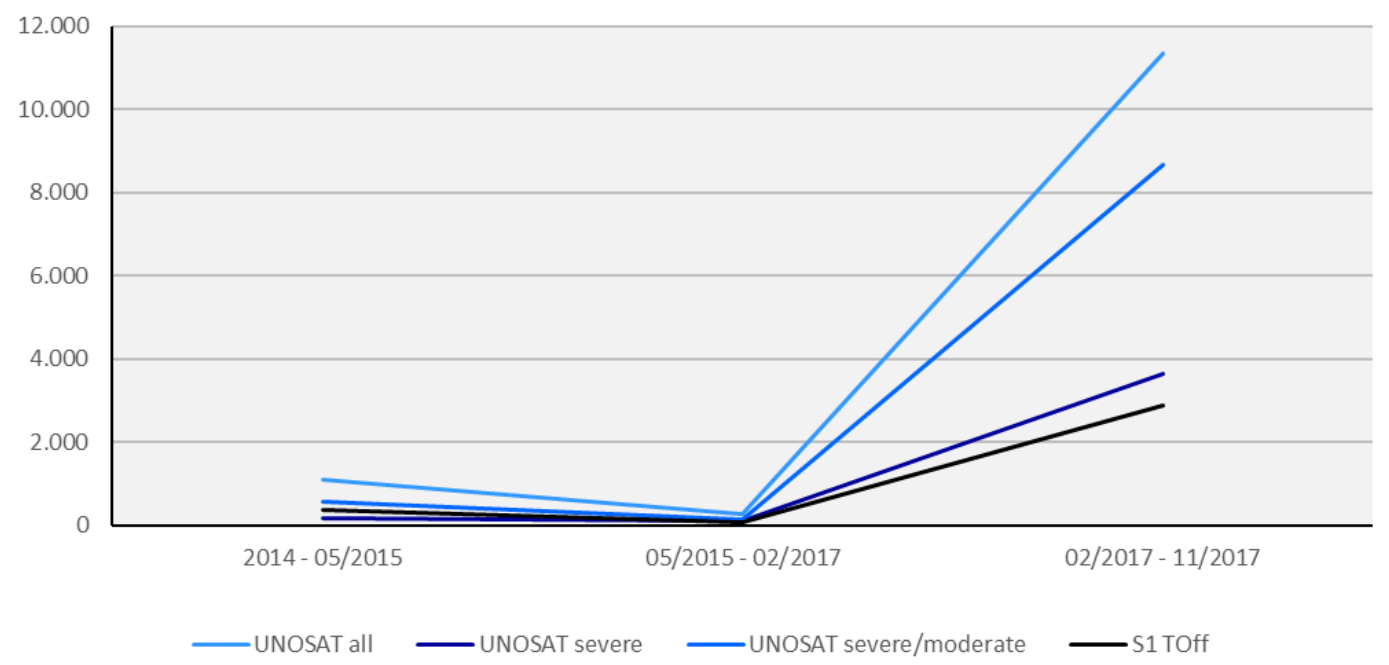

Figure 4: Number of changes identified by UNOSAT validation data (blue) and Sentinel-1 (black).

\section{Spatial changes}

Figure 5 shows the overall changes detected in the Sentinel-1 images (A) compared with the destroyed structures identified by UNOSAT (B). The results in map A are displayed as the sum of all changes in backscatter amplitude based on an image-by-image comparison over the period investigated. The results in map B were derived using a kernel density analysis (radius 150 metres) of points which were labelled as destruction of medium or very high confidence (see Table 2). The comparison shows that there is considerable agreement between the automatically derived changes and the manually identified damage, especially in the eastern part of the city. Mismatches can be observed in the north of the urban area, where the radar analysis did not detect large-scale damage. Additionally, in the UNOSAT data, damage is seen to gradually decrease towards the outskirts of the city. The reasons for the differences are discussed in section 5 . 

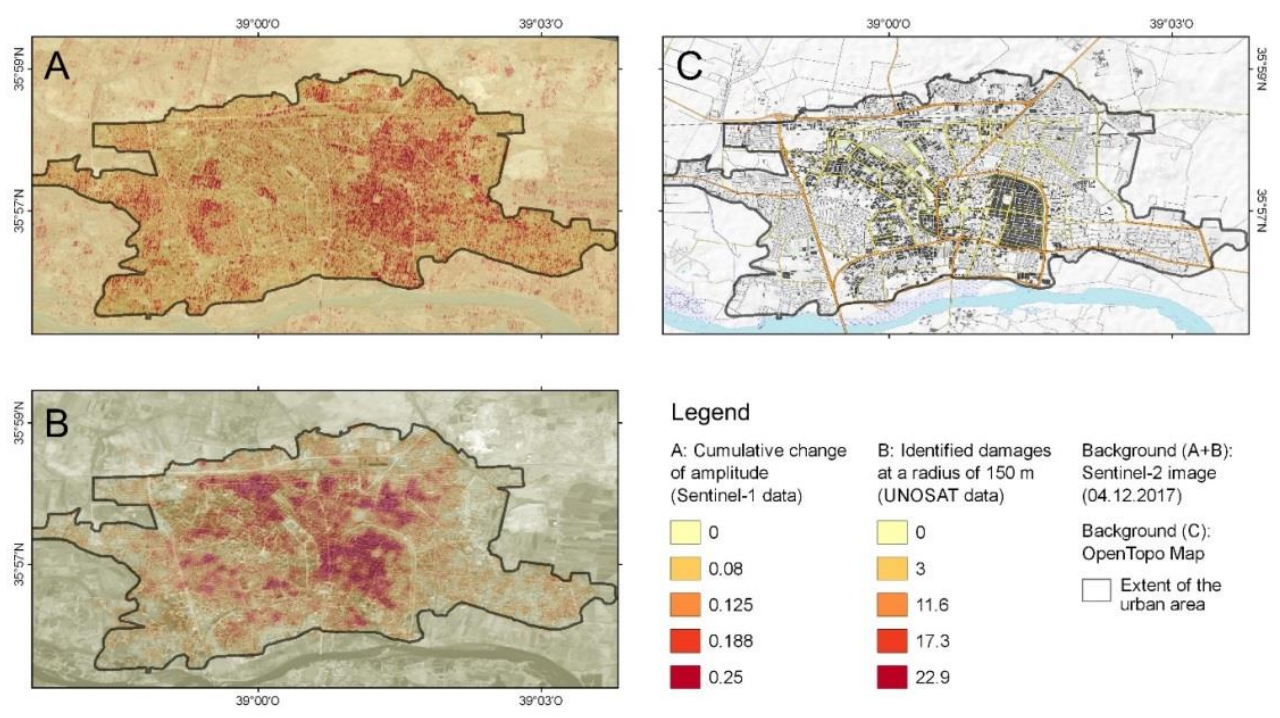

Figure 5: Overall changes identified by Sentinel-1 (A) and UNOSAT (B) in Raqqa during the period investigated.

\section{Changes at points of interest}

To demonstrate the potential of PS analyses for urban damage detection, seven sites were selected (see numbers in Figure 1, bottom right): two of the largest mosques in Raqqa (The Great Mosque [1] , and Al Firdous Mosque [2]), which were occupied during the civil war (Weinstein, 2017); the ancient ruins of Qasr al-Banat [3], where heavy combat took place (Perry \& Lawrence, 2017); the stadium [4], the basements of which were used as headquarters and jails (Walsh, 2017); the former IS command centre [5] (Walsh et al., 2017); two bridges [6-7] across the Euphrates in the south of the city. Life-times of PSs were analysed as well as their amplitude over the period studied to retrieve information on the location and date of potential damage.

\section{Significant buildings}

Analyses of both amplitude stability and life-time of pixels showed that no significant changes were detectable to the Al Firdous Mosque and the ruins of Qasr al-Banat, probably because the latter is already in a state of ruin, with generally low backscatter. The Great Mosque in the eastern part of the city, however, showed some indications of damage, as demonstrated in Figure 6. The large points indicate all PSs with a calculated end-date before 2018. Their amplitude stability is indicated in blue. After manual inspection, many of them were rejected because their amplitude values did not show a clear temporal pattern. The point marked in red is a good example of probable damage because of the clear decrease in amplitude (also called 'off-date'). The time-series graph (Figure 6, bottom right) shows that, based on the statistics of all 55 images, a significant change happened in July 2017 when the amplitude clearly decreased at the corner of the southern wall. This indicates that some of the massive minarets or walls collapsed. These findings coincide temporally with the second battle for Raqqa, from May to October 2017, during which the Great Mosque was reported 
to have been recaptured by US forces in September 2017 (Weinstein, 2017). This location was also labelled in the UNOSAT data as having been damaged, but before May 2015. We offer as a tentative explanation that the first damage was visually detectable in 2015 , but the collapse of this structure occurred later.

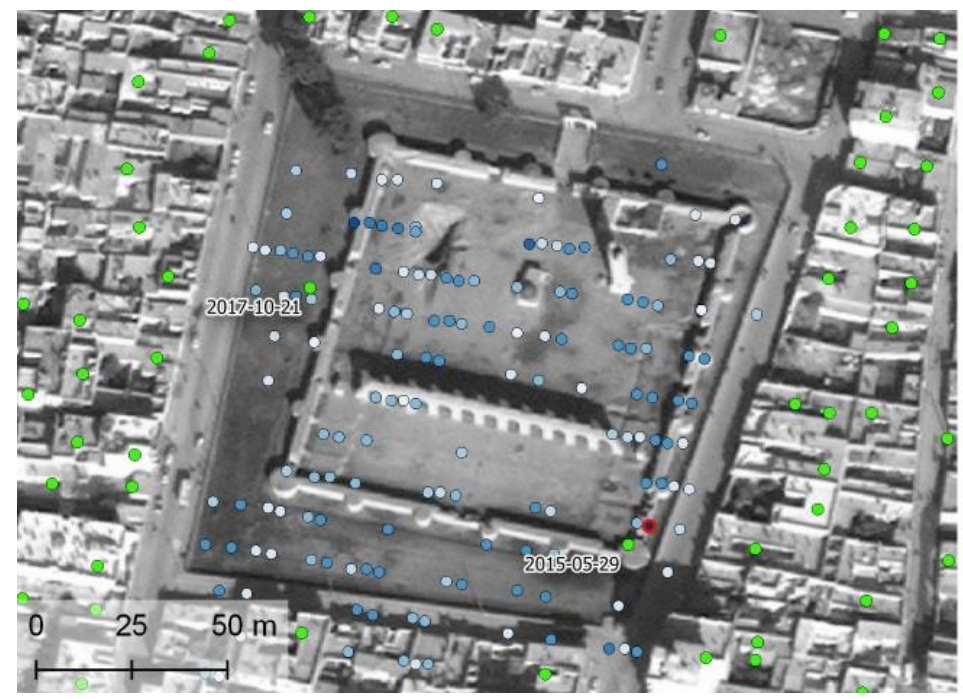

\section{Amplitude stability \\ High [1] \\ Low [0] \\ Date of damage \\ (UNOSAT)}

Basemap (c) Bing Maps 2018

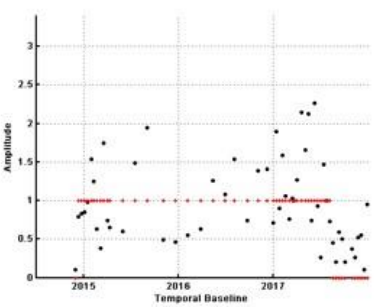

Figure 6: Amplitude stability of PS at the Great Mosque of Raqqa. The amplitude series of the location is marked in red, bottom right. The damage identified in the UNOSAT data is indicated in green, with selected dates. Note that the basemap image was taken before the civil war.

\section{Military infrastructure}

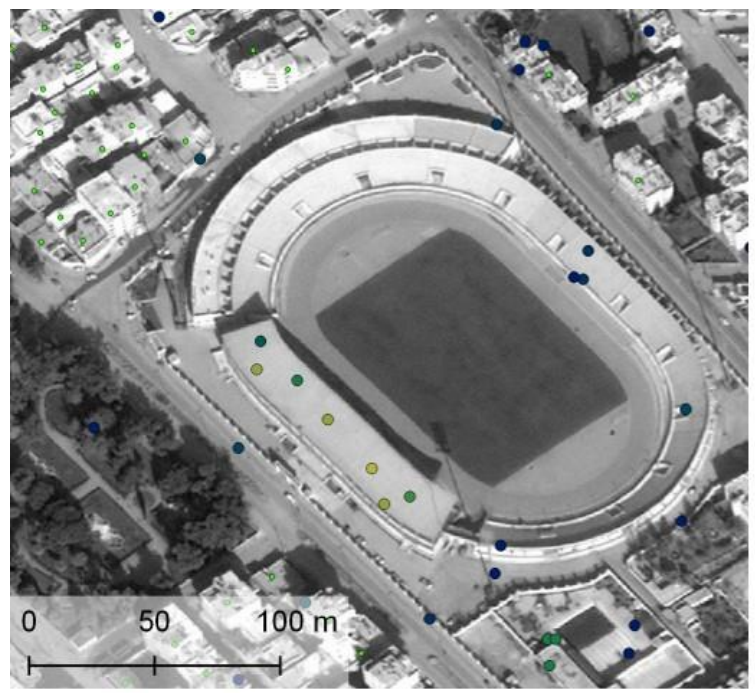

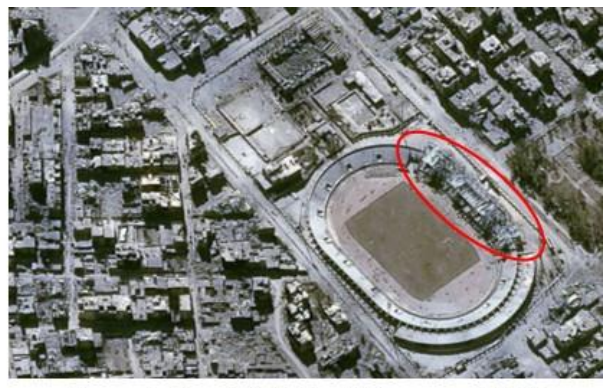

Drone footage CNN (Fox \& Munayyer 2017)

- Damage detected by UNOSAT

\section{Off-date}

$\begin{array}{llll}2015 & 2016 \quad 2017 \quad 2018\end{array}$

Basemap (C) Bing Maps 2018

Figure 7: Off-dates of PS around the Raqqa stadium (left), and drone footage of CNN (right). Note that the basemap image was taken before the civil war and shows the stadium from a different orientation. 
Figure 7 shows selected PSs around the Raqqa stadium. While the IS command centre did not show any damage during the period investigated, the stadium has a clear concentration of damage detected by Sentinel-1 imagery, along the roof of the grandstand. The colours indicate the date from when the backscattering within a pixel no longer occurred as a function of time. While the surroundings of the stadium were clearly affected at later times, the grandstand was apparently destroyed between November 2015 and May 2016. During that time, the city was under heavy fire as consequences of the Paris attacks and of an uprising against the occupation within the city (Abou Fadel, 2016). These findings are supported by drone footage released by CNN in late 2017 (Fox \& Munayyer, 2017). Notably, UNOSAT data did not include damage to the stadium.

\section{Bridges}

Of the two bridges in the south of Raqqa, the 'Old bridge' in the east shows considerable damage. Figure 8 shows that there are generally few PSs with Off-dates during the period studied, and many of them can be excluded because they are over the river itself and do not characterize the reflectance of the bridge. However, there are four PSs in the middle part of the bridge (shown in green, two of them highlighted by a red frame) which indicate clear damage in May and August 2017. Their amplitudes show a significant decrease compared to the many stable PSs on the bridge (exemplified by the yellow-framed circle). Due to the location of the bridge outside the city, it was not part of the UNOSAT analysis, but destruction of the bridge was later confirmed by aerial footage (Walsh et al., 2017).
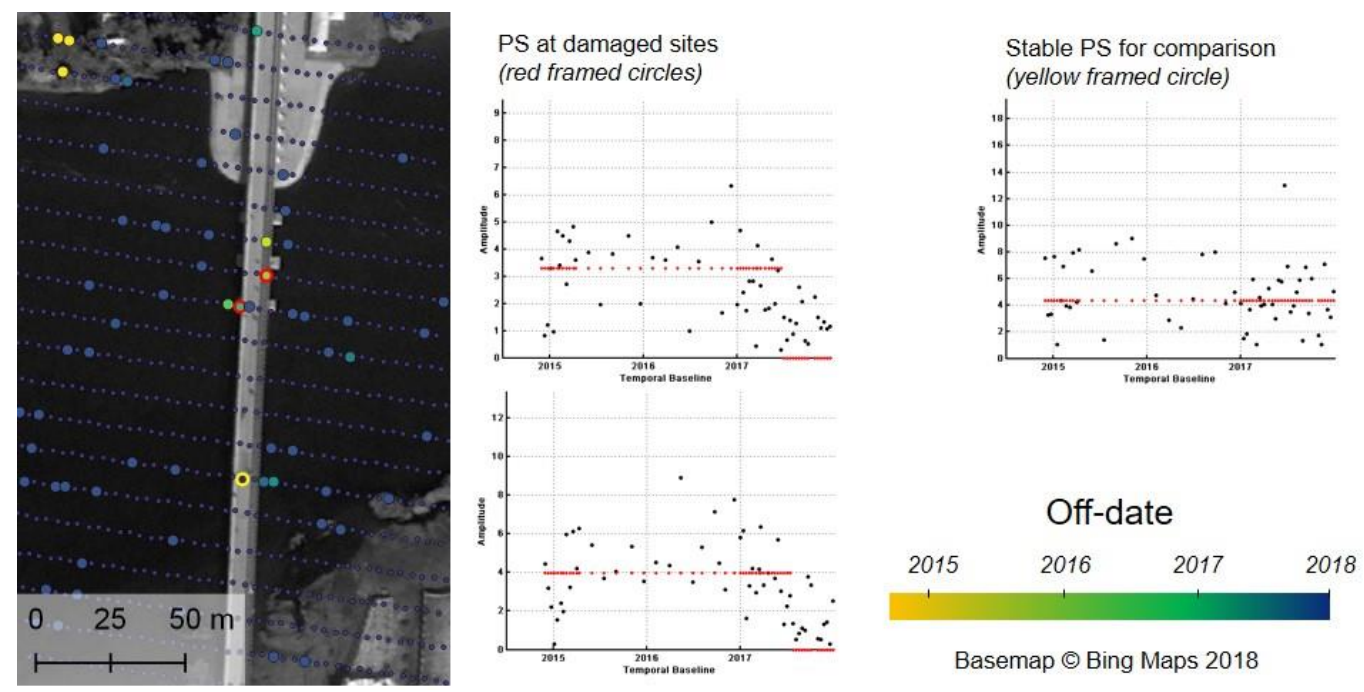

Figure 8: Off-dates of PSs at the Old Bridge in the southeast and amplitude time-series for selected points. Note that the basemap image was taken before the civil war. 


\section{Discussion and outlook}

This study has demonstrated how freely available Sentinel-1 data can be used to detect changes along time-series. Many established approaches in change detection are based on optical imagery or commercial SAR satellite sensors like TerraSAR-X or Cosmo SkyMed, which provide images at the metre scale and below. However, in our case, the high temporal resolution was found to compensate partly for the moderate spatial resolution of Sentinel-1 data. The data provided suitable indicators for damage within urban areas due to the high backscatter of built-up structures. However, there are some points to discuss.

As Figure 4 demonstrates, SAR data of this resolution cannot compete with the visual inspection of VHR imagery, especially when there is only light damage, such as cracks in roofs or limited missing parts of buildings which are otherwise intact.

However, these differences do not result just from the lower spatial resolution. It has to be kept in mind that optical sensors and radar satellites capture completely different features: while WorldView and Pléiades, used by UNOSAT, depend on the spectral diversity of surfaces, the microwaves of Sentinel-1 interact with the shape, size, orientation and material of objects. If none of these properties change in the case of a damaged building, there is no possibility of capturing any damage (Karimzadeh et al., 2017; Matsuoka \& Yamazaki, 2004). Of course, there are SAR-based approaches which utilize interferometric phase to obtain information about surface deformation (Hooper, 2008), or even changes at the building level (Gernhardt \& Bamler, 2012), but they all rely on either data of higher resolution or a-priori knowledge of the expected change (Fornaro et al., 2011).

Another point to bear in mind is the absence or reduced availability of persistent scatterers in urban areas that have lower building density or use light construction materials. As indicated in Figure 5, quarters with lower reflectivity are likely to be structurally excluded from the PS analysis. This can be partly solved by applying small baseline (SBAS) interferometry approaches, which are less dependent on strong scatterers (Ardizzone et al., 2012).

Regarding the time-series analysis, it should be noted that damage to a building does not necessarily mean an abrupt decrease of the amplitude to a level of zero. If an object only changes its height or orientation, there might just be lowered backscatter response (Ferro et al., 2011; Gernhardt et al., 2010).

The advantages of SAR-based approaches are obvious. The time required to extract areas of change is probably a fraction of that spent on manual interpretation or comparison of preand post-images. The high costs of commercial imagery might also be a determining factor for NGOs, which aim for cost-effective approaches. Lastly, manual analysis also carries the risk of misinterpretation or lack of objectivity (Yamazaki et al., 2005).

Since there are large numbers of studies demonstrating (semi-)automatic damage assessment based on VHR imagery of satellites (Tiede et al., 2011; Schöpfer et al., 2007) or UAVs (Fernandez Galarreta et al., 2015), one possible approach could be an integration of both optical and radar data for damage assessment. In the humanitarian domain, fusion methods have been used successfully to assess earthquake damage (Brunner et al., 2010) and landslides 
(Plank et al., 2016), and for urban mapping (Aravena Pelizari et al., 2018; Corbane et al., 2008).

Sentinel-1 imagery provides excellent image archives and freely available data, which increases the chance that pre-event data is available. However, its applicability in disaster mapping is constrained by the fact that there is not much time in cases of emergency. As shown in this study, at least two post-event images are required to automatically detect significant changes based on well-founded statistics. Concerning revisit rates, these would be once a month or less frequently, depending on the availability of both Sentinel-1 A and B data. However, human catastrophes require much shorter response times. Upcoming Sentinel-1 C and D missions could reduce this time to a more acceptable length.

On the other hand, we see a high demand for operational SAR sensors which regularly capture images of medium extent at spatial resolutions of around 5 metres. Images at that resolution are currently not taken at regular intervals, but they would certainly improve many applications in the humanitarian domain, because they allow an acceptable compromise between spatial coverage and temporal detail. If technological advancements continue as currently observed, this seems realistic in the medium-term. Until then, scientific institutions and organizations must continue to collaborate in developing further use-cases applications and services to assist the work of humanitarian operations.

\section{References}

Abou Fadel, L. (2016, March 6). Civilians rise up against ISIS rule in Raqqa City: government. AMN. URL: https://www.almasdarnews.com/article/civilians-rise-isis-rule-raqqa-city-government/

Aljazeera (2013, March 5). Syria rebels capture northern Raqqa city. URL: http://www.aljazeera.com/news/middleeast/2013/03/201334151942410812.html

Alvan, H. V., \& Azad, F. H. (2011). Satellite remote sensing in earthquake prediction. A review. In 2011 National Postgraduate Conference (pp. 1-5). IEEE. doi:10.1109/NatPC.2011.6136371

Amitrano, D., Di Martino, G., Iodice, A. [...], Koussoube, Y. (2013). Synthetic Aperture Radars for humanitarian purposes: Products and opportunities. Global Humanitarian Technology Conference (GHTC), 457-462.

Aravena Pelizari, P., Spröhnle, K., Geiß, C. [...], Taubenböck, H. (2018). Multi-sensor feature fusion for very high spatial resolution built-up area extraction in temporary settlements. Remote Sensing of Environment, 209, 793-807. doi:10.1016/j.rse.2018.02.025

Ardizzone, F., Bonano, M., Giocoli, A. [...], Solaro, G. (2012). Analysis of ground deformation using SBAS-DInSAR technique applied to COSMO-SkyMed images, the test case of Roma urban area. In C. Notarnicola, S. Paloscia, \& N. Pierdicca (Eds.): SPIE Proceedings (85360D). SPIE. doi:10.1117/12.979388

Boccardo, P., \& Giulio Tonolo, F. (2015). Remote Sensing Role in Emergency Mapping for Disaster Response. In G. Lollino, A. Manconi, F. Guzzetti, M. Culshaw, P. Bobrowsky, \& F. Luino (Eds.), Engineering Geology for Society and Territory. Urban Geology, Sustainable Planning and Landscape Exploitation (Volume 5, pp. 17-24). Cham: Springer International Publishing. doi:10.1007/978-3-319-09048-1_3

Boni, G., Castelli, F., Ferraris, L. [...], \& Siccardi, F. (2007). High resolution COSMO/SkyMed SAR data analysis for civil protection from flooding events. Geoscience and Remote Sensing Symposium, 2007. 
Brakenridge, G. R., Anderson, E., Nghiem, S. V. [...], Shabaneh, T. B. (2003). Flood warnings, flood disaster assessments, and flood hazard reduction: The roles of orbital remote sensing.

Braun, A., \& Hochschild, V. (2017). Potential and Limitations of Radar Remote Sensing for Humanitarian Operations. GI_Forum 2017, 1, 228-243. doi:10.1553/giscience2017_01_s228

Braun, A., Lang, S., \& Hochschild, V. (2016). Impact of Refugee Camps on Their Environment A Case Study Using Multi-Temporal SAR Data. Journal of Geography, Environment and Earth Science International, 4(2), 1-17. doi:10.9734/JGEESI/2016/22392

Brekke, C., \& Solberg, A. H.S. (2005). Oil spill detection by satellite remote sensing. Remote Sensing of Environment, 95(1), 1-13. doi:10.1016/j.rse.2004.11.015

Brunner, D., Lemoine, G., \& Bruzzone, L. (2010). Earthquake Damage Assessment of Buildings Using VHR Optical and SAR Imagery. IEEE Transactions on Geoscience and Remote Sensing, 48(5), 2403-2420. doi:10.1109/TGRS.2009.2038274

Chambers, J., Eddy, W., Härdle, W. [...], Fitzgerald, W. J. (1996). Numerical Bayesian Methods Applied to Signal Processing. New York, NY: Springer New York.

Corbane, C., Faure, J.-F., Baghdadi, N. [...], Petit, M. (2008). Rapid urban mapping using SAR/optical imagery synergy. Sensors, 8(11), 7125-7143.

Fernandez Galarreta, J., Kerle, N., \& Gerke, M. (2015). UAV-based urban structural damage assessment using object-based image analysis and semantic reasoning. Natural Hazards and Earth System Science, 15(6), 1087-1101. doi:10.5194/nhess-15-1087-2015

Ferretti, A., Perissin, D., Prati, C., \& Rocca, F. (2005). On the physical nature of SAR Permanent Scatterers. Symposium on Microwave Remote Sensing of the Earth, Oceans, Ice and Atmosphere, 20-27.

Ferretti, A., Prati, C., \& Rocca, F. (2001). Permanent scatterers in SAR interferometry. IEEE Transactions on Geoscience and Remote Sensing, 39(1), 8-20.

Ferro, A., Brunner, D., Bruzzone, L., \& Lemoine, G. (2011). On the relationship between double bounce and the orientation of buildings in VHR SAR images. IEEE Geoscience and Remote Sensing Letters, 8(4), 612-616.

Fornaro, G., Pauciullo, A., Reale, D. [...], Bamler, R. (2011). Peculiarities of urban area analysis with very high resolution interferometric SAR data. In 2011 Joint Urban Remote Sensing Event (pp. 185-188). IEEE. doi:10.1109/JURSE.2011.5764751

Fox, K., \& Munayyer, W. (2017, August 29). Raqqa in ruins: Drone footage reveals devastation in ISIS' stronghold in Syria. CNN. URL: https://edition.cnn.com/2017/08/29/middleeast/raqqadrone-footage-syria/index.html

Gernhardt, S., Adam, N., Eineder, M., \& Bamler, R. (2010). Potential of very high resolution SAR for persistent scatterer interferometry in urban areas. Annals of GIS, 16(2), 103-111. doi:10.1080/19475683.2010.492126

Gernhardt, S., \& Bamler, R. (2012). Deformation monitoring of single buildings using meterresolution SAR data in PSI. ISPRS Journal of Photogrammetry and Remote Sensing, 73, 68-79. doi:10.1016/j.isprsjprs.2012.06.009

Giles, P. T. (2001). Remote sensing and cast shadows in mountainous terrain. Photogrammetric Engineering \& Remote Sensing, 67(7), 833-840.

Hassan, H. (2017). The battle for Raqqa and the challenges after liberation. CTC Sentinel, 10(7), 1-10.

Henderson, F. M., \& Xia, Z.-G. (1997). SAR applications in human settlement detection, population estimation and urban land use pattern analysis: A status report. IEEE Transactions on Geoscience and Remote Sensing, 35(1), 79-85. doi:10.1109/36.551936

Hillenbrand, R. (1985). Eastern Islamic influences in Syria: Raqqa and Qal 'at Ja 'bar in the later 12th century. In J. Raby (Ed.), Oxford studies in Islamic art: Vol. 1. The art of Syria and the Jazira 1100 - 1250 (pp. 1100-1250). Oxford: Oxford University Press.

Hooper, A. (2008). A multi-temporal InSAR method incorporating both persistent scatterer and small baseline approaches. Geophysical Research Letters, 35(16). 
Joyce, K. E., Belliss, S. E., Samsonov, S. V. [...], Glassey, P. J. (2009). A review of the status of satellite remote sensing and image processing techniques for mapping natural hazards and disasters. Progress in Physical Geography, 33(2), 183-207. doi:10.1177/0309133309339563

Joyce, K. E., Wright, K., Ambrosia, V., \& Samsonov, S. V. (2010). Incorporating remote sensing into emergency management. The Australian Journal of Emergency Management, 25(4), 14-23.

Karimzadeh, S., Samsonov, S. V., \& Matsuoka, M. (2017). Block-based damage assessment of the 2012 Ahar-Varzaghan, Iran, earthquake through SAR remote senisng data. In 2017 IEEE International Geoscience and Remote Sensing Symposium (IGARSS) (pp. 1546-1549). IEEE. doi:10.1109/IGARSS.2017.8127264

Klemas, V. (2015). Remote Sensing of Floods and Flood-Prone Areas: An Overview. Journal of Coastal Research, 314, 1005-1013. doi:10.2112/JCOASTRES-D-14-00160.1

Lazecky, M., Hlavacova, I., Bakon, M. [...], Patricio, G. (2017). Bridge Displacements Monitoring Using Space-Borne X-Band SAR Interferometry. IEEE Journal of Selected Topics in Applied Earth Observations and Remote Sensing, 10(1), 205-210. doi:10.1109/JSTARS.2016.2587778

Lee, W. K. (2001). Analytical investigation of urban SAR features having a group of corner reflectors. Geoscience and Remote Sensing Symposium, IGARSS 2001, 3.

Lei, L., Perissin, D., \& Qin, Y. (2013). Change detection with spaceborne InSAR technique in Hong Kong. In 2013 IEEE International Geoscience and Remote Sensing Symposium - IGARSS (pp. 338-341). IEEE. doi:10.1109/IGARSS.2013.6721161

Lu, Z., Fatland, R., Wyss, M. [...], Freymueller, J. (1997). Deformation of New Trident Volcano measured by ERS-1 SAR interferometry, Katmai National Park, Alaska. Geophysical Research Letters, 24(6), 695-698.

Malsin, J. (2017, October 22). Raqqa is in ruins and ISIS in retreat. Time.

URL: http://time.com/raqqa-ruins-isis-retreat/

Martin, R. V. (2008). Satellite remote sensing of surface air quality. Atmospheric Environment, 42(34), 7823-7843. doi:10.1016/j.atmosenv.2008.07.018

Matsuoka, M., \& Yamazaki, F. (2004). Use of Satellite SAR Intensity Imagery for Detecting Building Areas Damaged Due to Earthquakes. Earthquake Spectra, 20(3), 975-994. doi:10.1193/1.1774182

Moser, L., Probeck, M., Ramminger, G. [...], Blaes, X. (2017). Sentinel-based Evolution of Copernicus Land Services on Continental and Global Scale.

Panetti, A., Rostan, F., L'Abbate, M. [...], Taini, G. (2014). Copernicus Sentinel-1 satellite and C-SAR instrument. Geoscience and Remote Sensing Symposium (IGARSS), 1461-1464.

Pearce, W. (1985). Cloud Shadow Effects on Remote Sensing. IEEE Transactions on Geoscience and Remote Sensing, GE-23(5), 634-639. doi:10.1109/TGRS.1985.289381

Perissin, D. (2018). Sarproz software. URL: www.sarproz.com

Perissin, D., \& Ferretti, A. (2007). Urban-target recognition by means of repeated spaceborne SAR images. IEEE Transactions on Geoscience and Remote Sensing, 45(12), 4043-4058. doi:10.1109/TGRS.2007.906092

Perissin, D., Ferretti, A., \& Prati, C. (Eds.) 2006. Spaceborne SAR anatomy of a city. : Vol. 610.

Perry, T., \& Lawrence, J. (2017, July 4). U.S.-backed Syrian force battles Islamic State in Raqqa's Old City. Reuters Group - Public Limited Company. URL: https://www.reuters.com/article/usmideast-crisis-syria-raqqa/u-s-backed-syrian-force-battles-islamic-state-in-raqqas-old-cityidUSKBN19P1G4

Plank, S., Martinis, S., \& Twele, A. (2016). Combining pre-event optical and post-event polarimetric SAR data for rapid landslide mapping.

Prati, C., Ferretti, A., \& Perissin, D. (2010). Recent advances on surface ground deformation measurement by means of repeated space-borne SAR observations. Journal of Geodynamics, 49(34), 161-170. doi:10.1016/j.jog.2009.10.011

Sato, M., Feng, X., \& \& Takahashi, K. (2008). 3D subsurface SAR for humanitarian demining. 7th European Conference on Synthetic Aperture Radar (EUSAR), 1-4. 
Scaioni, M., Longoni, L., Melillo, V., \& Papini, M. (2014). Remote Sensing for Landslide Investigations: An Overview of Recent Achievements and Perspectives. Remote Sensing, 6(10), 9600-9652. doi:10.3390/rs6109600

Schöpfer, E., Tiede, D., Lang, S., \& Zeil, P. (2007). Damage assessment in townships using VHSR data; The effect of Operation Murambatsvina / Restore Order in Harare, Zimbabwe. In 2007 Urban Remote Sensing Joint Event (pp. 1-5). IEEE. doi:10.1109/URS.2007.371846

Tiede, D., Lang, S., Füreder, P. [...], Zeil, P. (2011). Automated Damage Indication for Rapid Geospatial Reporting. Photogrammetric Engineering \& Remote Sensing, 77(9), 933-942. doi:10.14358/PERS.77.9.933

Tronin, A. A. (2006). Remote sensing and earthquakes: A review. Physics and Chemistry of the Earth, 31(4-9), 138-142. doi:10.1016/j.pce.2006.02.024

Ulaby, F. T., Moore, R. K., \& Fung, A. K. (1982). Microwave remote sensing: Active and passive. Vol. 2, Radar remote sensing and surface scattering and emission theory: Addison-Wesley Reading, MA.

UNITAR. (2017). Damage density of Ar Raqqa, Ar Raqqa governorate, Syria: UNOSAT Product ID 2742. 28.11.2017. URL: http://www.unitar.org/unosat/map/2742

Walsh, N. P. (2017, October 20). Inside the Raqqa jail where ISIS held their betrayers. CNN. URL: https://edition.cnn.com/2017/10/20/middleeast/inside-raqqas-isis-jail/index.html

Walsh, N. P., van Heerden, D., \& Abdelaziz, S. (2017, April 25). Satellite captures rare snapshot of life in Raqqa. CNN. URL: https://edition.cnn.com/2017/04/25/middleeast/raqqa-satelliteimages/index.html

Wegmuller, U., Wiesmann, A., Strozzi, T., \& \& Werner, C. (2002). ENVISAT ASAR in disaster management and humanitarian relief. Geoscience and Remote Sensing Symposium, 2002. IGARSS'02., 2282-2284.

Weinstein, A. (2017, September 5). US-led coalition takes Raqqa's Grand Mosque away from ISIS. Business Insider . URL: http://www.businessinsider.de/us-led-coalition-takes-raqqas-grandmosque-away-from-isis-2017-9? r=US\&IR=T

Wiesmann, A., Wegmuller, U., Haeberlin, Y. [...], \& Werner, C. (2004). SAR based products for the implementation of humanitarian aid and development assistance projects within the UNOSAT project. Geoscience and Remote Sensing Symposium, 2004. IGARSS'04., 4803-4806.

Wulder, M. A., White, J. C., Goward, S. N. [...], Woodcock, C. E. (2008). Landsat continuity: Issues and opportunities for land cover monitoring. Remote Sensing of Environment, 112(3), 955-969. doi:10.1016/j.rse.2007.07.004

Xie, Y., Sha, Z., \& Yu, M. (2008). Remote sensing imagery in vegetation mapping: A review. Journal of plant ecology, 1(1), 9-23.

Yamazaki, F., Yano, Y., \& Matsuoka, M. (2005). Visual Damage Interpretation of Buildings in Bam City Using QuickBird Images Following the 2003 Bam, Iran, Earthquake. Earthquake Spectra, 21(S1), 329-336. doi:10.1193/1.2101807

Yonezawa, C., \& Takeuchi, S. (2001). Decorrelation of SAR data by urban damages caused by the 1995 Hyogoken-nanbu earthquake. International Journal of Remote Sensing, 22(8), 1585-1600. 